UCRL-JC-123080

PREPRINT

$$
\text { CONF- } 9606116--85
$$

\title{
Recent Performance Results of the National Ignition Facility Beamlet Demonstration Project
}

RECEIVED

SEP 201996

B. M. Van Wonterghem, P. J. Wegner, J. K. Lawson, J. M. Auerbach,

M. A. Henesian, C. E. Barker, C. E. Thompson, C. C. Widmayer, J. A. Caird

This paper was prepared for submittal to the

Proceedings of the 1996 American Nuclear Society Meeting and 12th Topical

Meeting on the Technology of Fusion Energy

Reno, NV

June 16-20, 1996

August 21, 1996

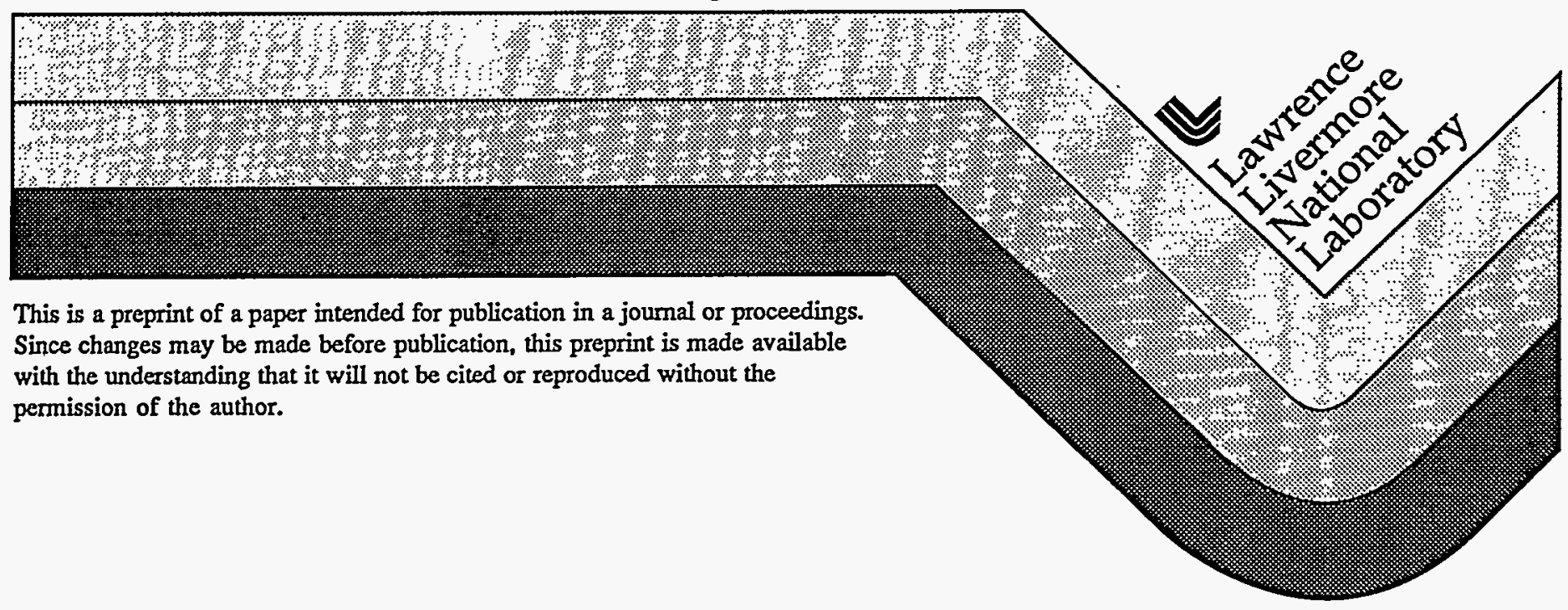

L.6421: v1.0 (3/96) 


\section{DISCLAIMER}

This report was prepared as an account of work sponsored by an agency of the United States Government. Neither the United States Government nor any agency thereof, nor any of their employees, make any warranty, express or implied, or assumes any legal liability or responsibility for the accuracy, completeness, or usefulness of any information, apparatus, product, or process disclosed, or represents that its use would not infringe privately owned rights. Reference herein to any specific commercial product, process, or service by trade name, trademark, manufacturer, or otherwise does not necessarily constitute or imply its endorsement, recommendation, or favoring by the United States Government or any agency thereof. The views and opinions of authors expressed herein do not necessarily state or reflect those of the United States Government or any agency thereof. 


\section{DISCLAIMER}

Portions of this document may be illegible in electronic image products. Images are produced from the best available original document. 


\title{
Recent Performance Results of the National Ignition Facility \\ Beamlet Demonstration Project
}

\author{
B.M. Van Wonterghem, P.J. Wegner, J.K. Lawson, J.M. Auerbach, M.A. Henesian, \\ C.E. Barker, C.E. Thompson, C.C. Widmayer, J.A. Caird
}

\author{
University of California \\ Lawrence Livermore National Laboratory \\ Livermore CA 94550
}

This paper was submitted to the

Proceedings of the 1996 American Nuclear Society Meeting and 12th Topical Meeting on the Technology of Fusion Energy, Reno Nevada, June 16-20, 1996 


\title{
Recent Performance Results of the National Ignition Facility
}

\author{
Beamlet Demonstration Project
}

\section{B.M. Van Wonterghem, P.J. Wegner, J.K. Lawson, J.M. Auerbach, M.A. Henesian, C.E. Barker, C.E.} Thompson, C.C. Widmayer, and J.A. Caird

University of California, Lawrence Livermore National Laboratory, Livermore CA 94550

\section{ABSTRACT}

The laser driver for the National Ignition Facility will be a departure from previous inertial confinement fusion laser architecture of a master-oscillator single-pass power-amplifier (MOPA) design. The laser will use multi-segment Nd:Glass amplifiers in a multipass cavity arrangement, which can be assembled into compact and cost-effective arrays to deliver the required multimegajoule energy to target. A single beam physics prototype, the Beamlet, has been in operation for over two years and has demonstrated the feasibility of this architecture. We present a short review of Beamlet's performance and limitations based on beam quality both at its fundamental and frequency converted wavelengths of 1.053 and $0.351 \mu \mathrm{m}$.

\section{INTRODUCTION}

Beamlet is a single-aperture beamline Nd:Glass laser system that functions as a scientific prototype of a new class of fusion laser drivers. Its architecture is based on the use of components with a single aperture size. The beam propagates multiple passes through the largest aperture amplifier, rather than through a chain of amplifiers of increasing size. Multipass amplification is achieved by building a cavity around the main amplifiers. This type of architecture proves to be cost effective and most suitable to stack amplifier chains into compact powerful arrays, designed to deliver large amounts of energy on target after frequency conversion of the $1.05 \mu \mathrm{m}$ beam to $0.351 \mu \mathrm{m}$. The National Ignition Facility laser driver design applies this architecture to deliver $1.8 \mathrm{MJ}$ of $351 \mathrm{~nm}$ light using 192 beams, for the purpose of achieving ignition and thermonuclear burn of ICF targets ${ }^{1,2}$.

The actual Beamlet design as shown in Figure 1 is very close to the NIF driver design ${ }^{3}$. The laser consists of two main amplifier blocks: the cavity amplifier and the booster amplifier. Fluence limitations on the cavity polarizer prevent us from keeping all amplifiers within the multipass cavity. The cavity amplifier consists of 11 Brewster-oriented amplifier slabs, and is located in a $36 \mathrm{~m}$

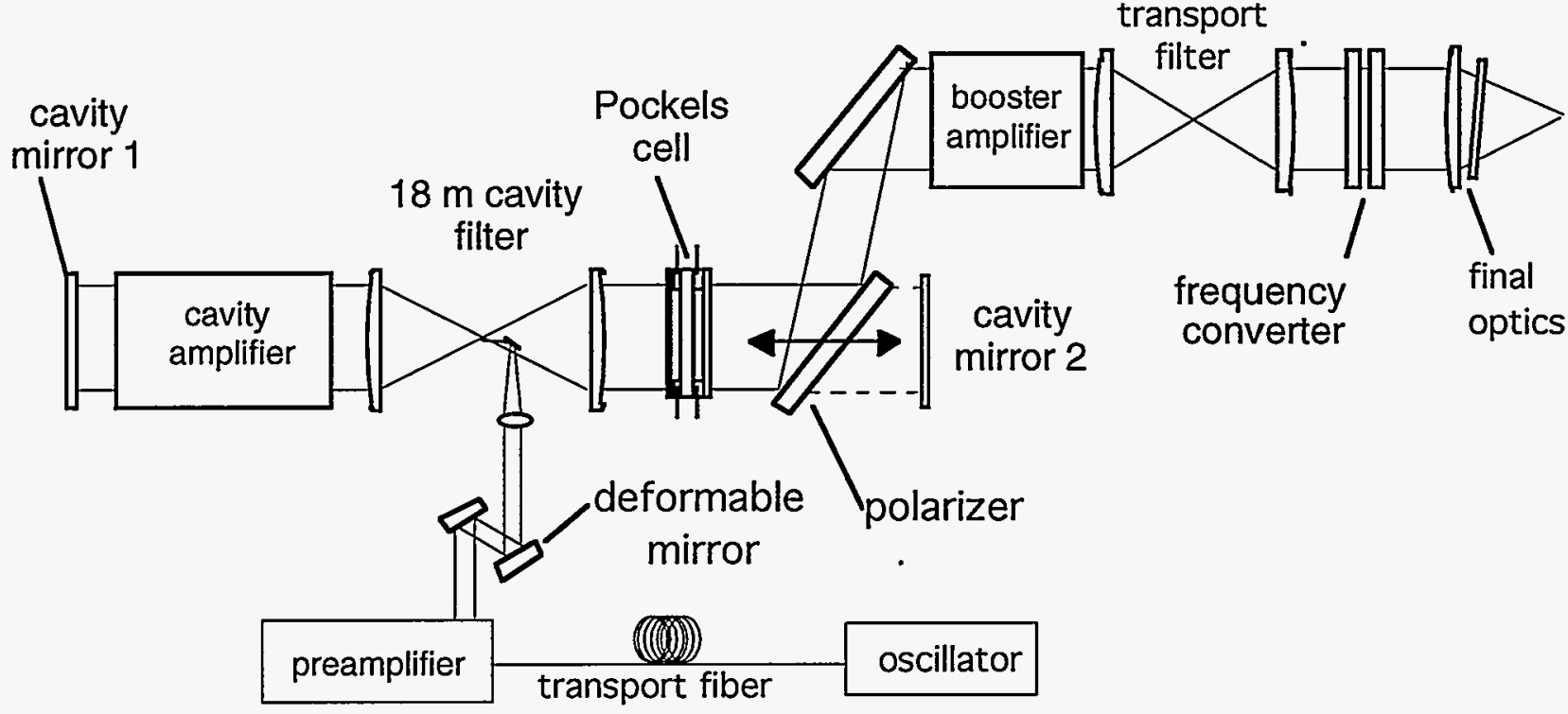

Figure 1. Schematic layout of the Beamlet prototype multi-pass amplifier laser system. 
long cavity consisting of two end mirrors, a spatial filter image relay, and an optical switch to dump the beam out of the cavity after 4 passes. The beam is then amplified further in a 5-slab long booster amplifier, and imaged into a KDP (Potassium-DiHydrogen-Phosphate)-KD*P (80\% deuterated KDP) frequency converter. The $0.351 \mu \mathrm{m}$ beam is then focussed into a vacuum vessel, equipped with an equivalent plane diagnostic system to characterize target plane irradiance. The Beamlet prototype has demonstrated the functionality of the main components for a multipass amplifier. Beamlet's multi-segment amplifiers are build up of individual 2 aperture wide by 2 aperture high units ${ }^{4}$. Only one of the four apertures however is equipped with real Nd:Glass slabs. A large aperture Pockels cell uses transparent plasma electrodes on either side of a $1 \mathrm{~cm}$ thick KDP crystal to obtain a very uniform switching efficiency over its $36 \mathrm{~cm} \times 36 \mathrm{~cm}$ clear apertures. The average switching efficiency exceeds $99.5 \%$. In addition several new techniques have been applied to improve beam quality. These include the use of integrated optical circuits to provide flexible temporal pulse shaping, fiber optic beam transport, high gain multipass preamplifier systems, an adaptive optics wavefront control system ${ }^{6}$ and spatial beam profile shaping to compensate for gain variation over the aperture of the amplifiers.

The actual design details of an individual NIF beamline differ from Beamlet in a number of ways. The $\mathrm{NIF}$ amplifier configuration uses 2 more amplifier slabs in the booster section to extend the operating regime to higher fluences, it has a much longer transport spatial filter $(60 \mathrm{~m})$ to span the distance to the NIF target chamber, and an effective beam area $23 \%$ larger than Beamlet, i.e. $38 \mathrm{~cm}$ beam size rather than $35 \mathrm{~cm}$. Beamlet can actually propagate beam sizes ranging from 29.5 up to $35 \mathrm{~cm}$, based on experimental requirements. Section VI covers some of the future changes that will be implemented on Beamlet to make the extrapolation to the NIF beamlet even smaller, especially in the final optics section of the laser (frequency converter and $0.351 \mu \mathrm{m}$ focusing optics).

\section{BEAMLET $1.05 \mu \mathrm{m}$ LASER PERFORMANCE}

The multipass architecture, as shown in Figure 1 , has a number of design parameters that can be altered to optimize the energy/intensity performance for a particular pulse length and shape. The limitations to this optimization are stored energy in the laser slabs, the optical damage threshold of the individual components, and the nonlinear growth of the beam modulation (Bintegral effect). Beamlet was designed to provide optimum performance for a temporally square $3 \mathrm{~ns}$ output pulse. At this operating point both B-integral in the cavity and the booster section are at a set limit, and the fluence of the cavity polarizer is at nearly $70 \%$ of its safe operating fluence limit ( $11 \mathrm{~J} / \mathrm{cm}^{2}, 3 \mathrm{~ns}$ pulse). Figure 2 shows a calculated safe Beamlet performance curve for square output pulses plotted in intensity versus fluence space, and data points from appr. 500 shots. Except for two small spots, no damage has been observed on the polarizer during 2.5 years of operation. The calculations are based on either a nonlinear phase shift between spatial filters, $\Delta \mathrm{B}$, equal to 2 radians, or a damage threshold limitation for the multi-pass cavity switch polarizer. The actual safe $\Delta B$ limit depends on a number of factors, and will be discussed in sect. III. Shots of equal pulse

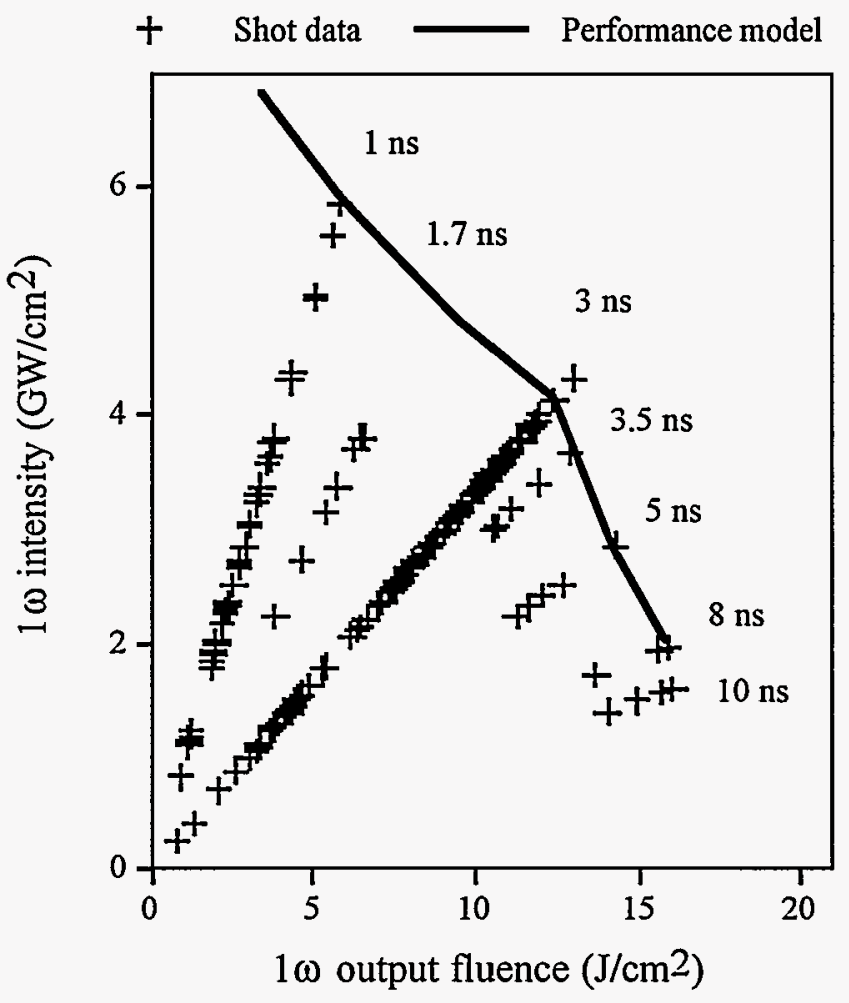

Figure 2. Performance curve and shot data of the Beamlet laser system at $1.05 \mu \mathrm{m}$.

duration are located on lines though the origin. At low fluences (pulse duration below $3 \mathrm{~ns}$ ), $\Delta \mathrm{B}$ in the booster amplifier section is the limiting factor. As the fluence (and pulse duration increases), the input power needs to be temporally shaped to compensate for gain saturation, leading to lower intensity limits.

Typically, near field and focal spot images of the output beam are recorded to evaluate the laser performance on a particular shot. Figure 3 shows the measured near field beam fluence for a $3 \mathrm{~ns}$ pulse at $12.3 \mathrm{~J} / \mathrm{cm}^{2}$, close to the operating limit discussed above. A corresponding histogram of the average normalized fluence indicates a quite small peak modulation of $1.3: 1$, in good agreement with the results of a detailed propagation model.

The focal spot images measure the distribution of the beam's divergence. Figure 4 shows the central area of 

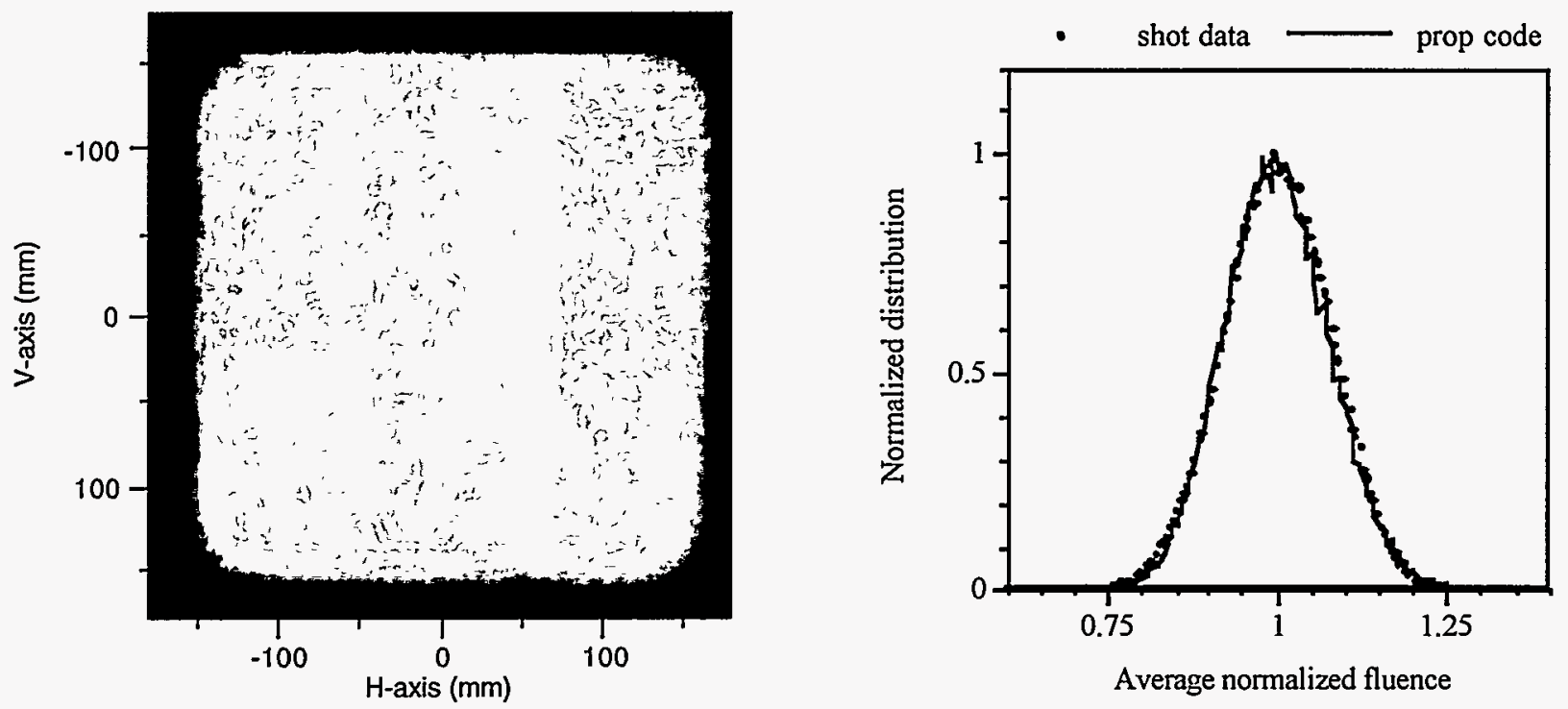

Figure 3. Near field output beam image and fluence distribution of a $3 \mathrm{~ns}, 12.4 \mathrm{~J} / \mathrm{cm} 2$ Beamlet shot at $1.05 \mu \mathrm{m}$ at the frequency converter plane.

a typical $1.05 \mu \mathrm{m}$ beam focal spot. A deformable mirror located in the cavity injection optics is used to correct the shot wavefront for low order static aberrations in the optics, residual thermal distortions in the amplifiers slabs from previous shots, and instantaneous, pump induced
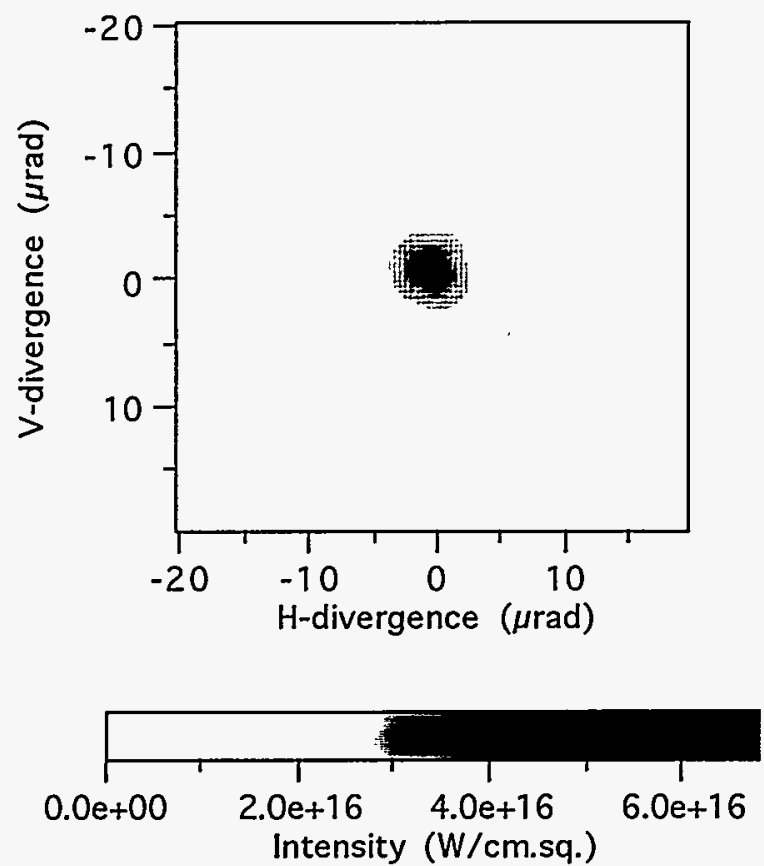

Figure 4. $1.05 \mu \mathrm{m}$ beam far field image of a $1.5 \mathrm{TW}$, 3 ns shot with full precorrection for static and pump induced wavefront aberrations. RMS wavefront aberration was $0.17 \lambda$. aberrations in the large amplifiers of the laser. The resulting Strehl ratio of the $1.05 \mu \mathrm{m}$ beam can be as high as 0.4 with over $95 \%$ of the beam energy contained inside a cone with half angle of $22.5 \mu \mathrm{rad}$ (Figure 4). The spatial resolution of the 39 actuator deformable mirror is limited to $\pm 20 \mu \mathrm{rad}$. A small fraction of the small-angle scattering at larger angles cannot be corrected, and needs to be minimized through the use of high quality optical components, and through spatial filtering. Depending on the angle, this energy fraction can be amplified by nonlinear effects at high intensity, leading to increased beam modulation at small spatial scale lengths. For Beamlet, noise with spatial scale length near $5 \mathrm{~mm}$ (corresponding to a divergence angle of $220 \mu \mathrm{rad}$ ) sees the highest nonlinear gain. Figure 5 shows an azimuthally averaged far field intensity distribution of a $3.7 \mathrm{GW} / \mathrm{cm}^{2}$ short pulse shot. The different beam divergence regions discussed above are highlighted in the graph.

\section{RECENT INVESTIGATIONS OF PERFORMANCE LIMITS AT $1.05 \mu \mathrm{m}$}

Nonlinear modulation growth depends on $\Delta B$, and for a square output pulse, reaches a peak during the last time slice of the pulse The imaging diagnostics as discussed above are inadequate to evaluate this noise growth and the $\Delta \mathrm{B}$-limits of the laser for long pulses. An extensive experimental campaign and theoretical analysis was launched to investigate these conditions using short $200 \mathrm{ps}$ pulses propagated under conditions simulating the worst case for noise growth, and is described elsewhere in these proceedings by Widmayer etal. ${ }^{8}$. The results demonstrate that by limiting high angle scattering through appropriate spatial filtering of the beams, and by 


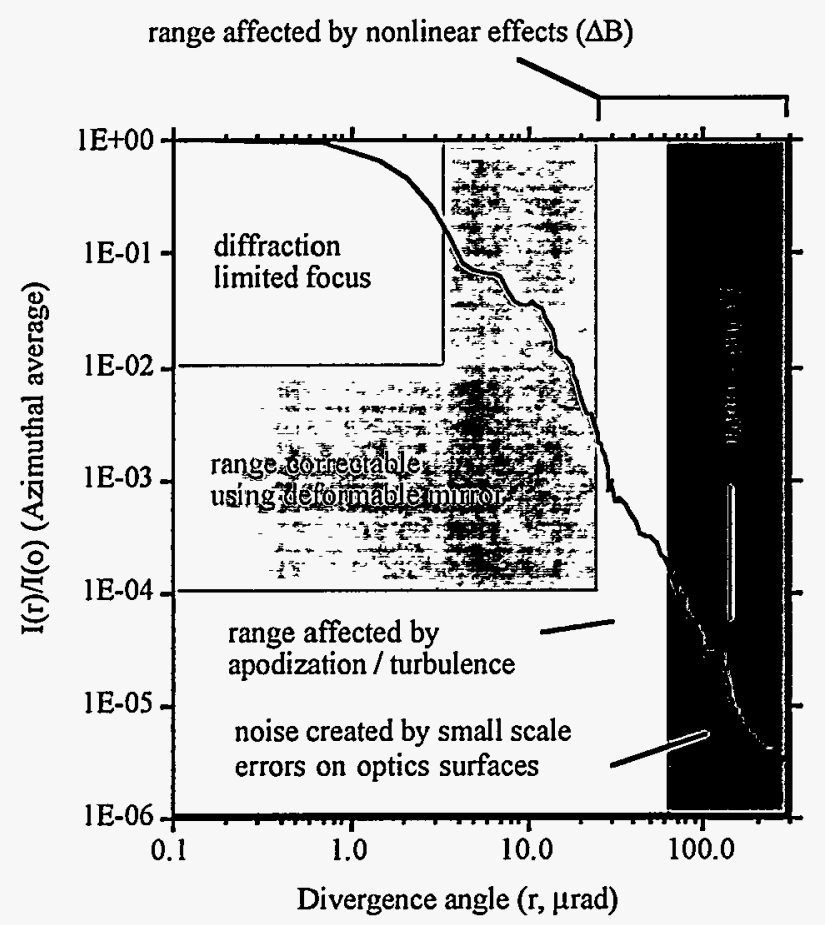

Figure 5. Azimuthally averaged intensity distribution of the $1.05 \mu \mathrm{m}$ beam far field. The central peak represents the main lobe of a diffraction limited far field distribution. The function of the deformable mirror is to increase the energy fraction inside this spot. Beam edge effects and turbulence in beamtubes and amplifiers scatter energy in the 25-60 $\mu \mathrm{rad}$ region. Spatial filter pinholes limit nonlinear growth at the high end of the beam divergence distribution.

using components with low surface roughness, on the order of $10 \AA$ RMS measured over scale lengths of 33 to $0.12 \mathrm{~mm}$, high quality beams can be obtained under operating conditions consistent with NIF red-line performance requirements.

\section{SPATIAL FILTERING OF HIGH INTENSITY AND ENERGY BEAMS}

Spatial filtering has been used in most large laser systems to improve beam quality, and suppress small scale self-focusing ${ }^{9}$. It is important that the intensity at the edge of the pinhole be sufficiently small to ensure successful operation at high powers and long pulse durations $(\Delta t>3 n s)$. Clipped energy fractions of $1 \%$ or higher level lead to near field modulation at the pinhole cut-off frequency after the spatial filter, known as Gibb's modulation. In addition, a low density plasma generated at the pinhole edges, propagates into the pinhole aperture, where it can eventually lead to beam degradation and pinhole closure on a time scale of several nanoseconds. Beamlet has demonstrated several technologies that minimize the level of edge irradiation at the pinholes: correction of low order wavefront aberrations, low level of scattering by optical components, and the application of a staged spatial filtering scheme that uses consecutively smaller pinholes through the multipass cavity and transport section. Figure 6 illustrates the effect of tight $\pm 100 \mu \mathrm{rad}$ spatial filtering on the output $1.05 \mu \mathrm{m}$ beam of a short $200 \mathrm{ps}$ pulse at an intensity of $4.3 \mathrm{GW} / \mathrm{cm}^{2}$ with unpumped booster amplifiers.

The NIF indirect drive pulse will have a typical duration of $20 \mathrm{~ns}$ and will consist of a $17 \mathrm{~ns}$ foot followed by a $3 \mathrm{~ns}$ main pulse. Beamlet will investigate spatial filtering cut-off limits for this type of shaped pulse. Offline experiments performed on the Janus facility in Livermore have demonstrated feasibility of advanced pinhole designs that delay the time to closure by a factor three compared to the conventional washer type pinholes used in Beamlet spatial filters ${ }^{10}$.

\section{PERFORMANCE AND BEAM QUALITY AT 0.351 $\mu \mathrm{m}$}

Efficient energy conversion on target is achieved with frequency tripled radiation $(0.351 \mu \mathrm{m})$. This requires an efficient and large dynamic range frequency conversion process. Beamlet and NIF adopted a type I/ Type II frequency tripling scheme that uses a KDP doubler and $\mathrm{KD}^{*} \mathrm{P}$ tripling crystal ${ }^{11}$. Initial tests propagated a $29.5 \mathrm{x}$ $29.5 \mathrm{~cm}^{2}$ size beam through $32 \times 32 \mathrm{~cm}^{2}$ monolithic crystals, and were followed by characterization of $37 \times 37$ $\mathrm{cm}^{2}$ crystals with a $34 \times 34 \mathrm{~cm}^{2}$ size beam. Four important issues were addressed during these initial experiments: conversion efficiency, damage threshold of the crystals, near field beam quality and transverse stimulated Raman scattering (SRS) in the tripling crystal $^{12}$. Whole-beam frequiency tripling efficiencies near $80 \%$ were obtained using 3 ns square drive pulses at intensities near $3.5 \mathrm{GW} / \mathrm{cm}^{2}$, with peak efficiencies exceeding $83 \%$.

Beamlet has generated a maximum $0.351 \mu \mathrm{m}$ energy of $8.3 \mathrm{~kJ}$ in a $1000 \mathrm{~cm}^{2}$ effective area beam, corresponding to $10.8 \mathrm{~kJ}$ in a NIF sized beam. Beamlet $\mathrm{KDP}$ and $\mathrm{KD}^{* \mathrm{P}}$ samples have demonstrated excellent damage resistance both at 1.05 and $0.351 \mu \mathrm{m}$. A multiple shot on-line conditioning procedure is instrumental to obtain these damage thresholds. The frequency tripling crystal has been operated at average $0.351 \mu \mathrm{m}$ fluences up to $8.7 \mathrm{~J} / \mathrm{cm}^{2}$ with peak fluences exceeding $12 \mathrm{~J} / \mathrm{cm}^{2}$ (3ns square pulse) without noticeable damage. Near field fluence modulation of the $0.351 \mu \mathrm{m}$ beam was very close to the fluence modulation of the $1.05 \mu \mathrm{m}$ drive beam near maximum operating regime, and found to be $1.35: 1$ at the exit face of the tripler crystal.

A sufficiently high intensity $0.351 \mu \mathrm{m}$ beam can excite transverse stimulated Raman scattering in the frequency tripler, perpendicular to the polarization vector 


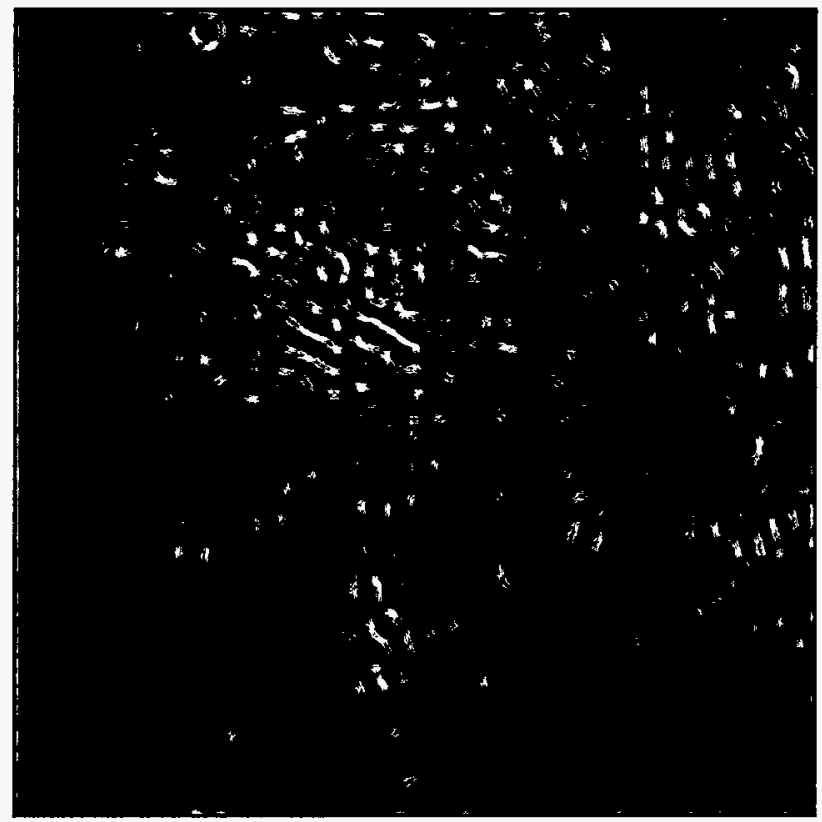

Figure 6.a Modulation of a high intensity short pulse $1.05 \mu \mathrm{m}$ beam at the frequency converter location. The beam propagated through the booster amplifier without further spatial filtering in the transport spatial filter. Peakto-average modulation is up to $3: 1$, and close to the onset of small scale self-focusing.

of the $0.351 \mu \mathrm{m}$ beam. This scattering can lead to damage of the tripler edges and loss in conversion efficiency. Measured values of the gain coefficient in the $80 \%$ deuterated tripler crystal ranged from 0.090 to 0.098 $\mathrm{cm} / \mathrm{GW}$. The SRS scattering did not prove to be a significant problem during the Beamlet experiments ${ }^{13}$.

More recently, the final optics section of Beamlet was modified to field experiments investigating the focal plane irradiance distribution of the $0.351 \mu \mathrm{m}$ beam using a geometry close to the NIF design. A square wedged $7 \mathrm{~m}$ focal length lens brings the $0.351 \mu \mathrm{m}$ beam to a focus in a vacuum vessel and separates the residual fundamental and frequency doubled beams. A large aperture diagnostic telescope images the focal spot with high resolution into a series of diagnostics, designed to evaluate $0.351 \mu \mathrm{m}$ near field modulation and beam divergence. Kinoform phase plates have been tested to reshape the focal plane irradiance pattern improving the uniformity of target illumination ${ }^{14}$. An experimental campaign is in progress to evaluate $0.351 \mu \mathrm{m}$ beam quality under the most stressing conditions of the NIF ignition drive pulse shape. The goal of these experiments is to verify filamentation risk in the final optics, and investigate NIF indirect drive target plane irradiance requirements. A more detailed account of these experiments and preliminary results have been described by Wegner etal. elsewhere in these proceedings ${ }^{15}$.

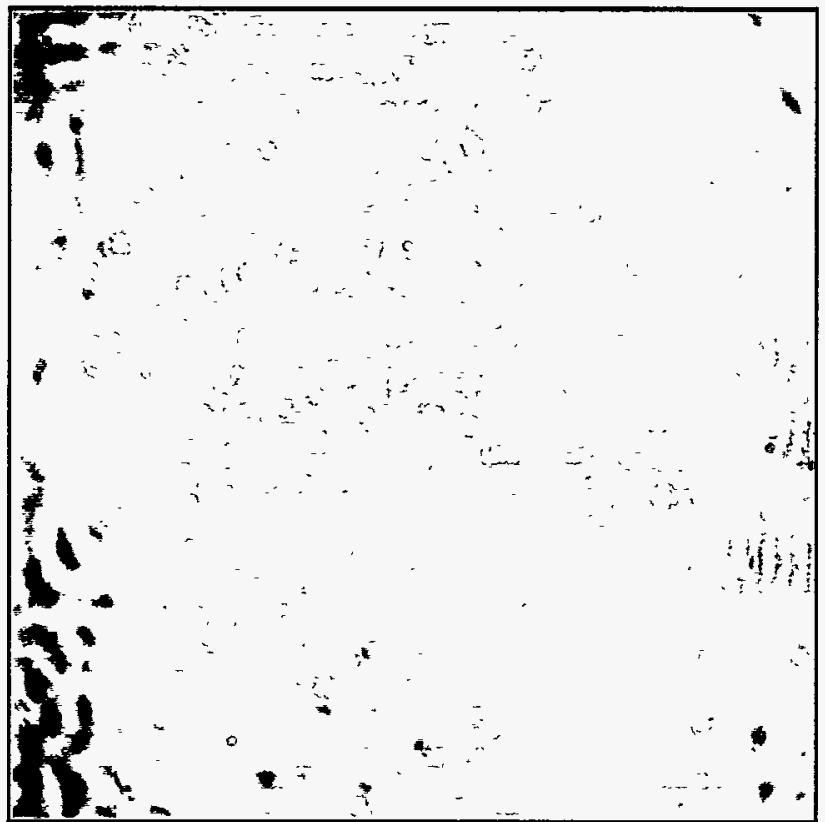

Figure 6.b Image of a beam with the same intensity and amplifier configuration as the beam shown on Fig 6.a, but using a $\pm 100 \mu \mathrm{rad}$ spatial filtering cut-off angle in the transport spatial filter. Beam quality is restored and peakto-average modulation is reduced to $1.3: 1$.

\section{CONCLUSION AND FUTURE BEAMLET EXPERIMENTS}

Beamlet has demonstrated the architecture and major components for a new large aperture Nd:Glass multipass amplifier based driver for ICF applications. As a scientific prototype for the National Ignition Facility driver design, it has been used to demonstrate the required beam quality both at 1.05 and $0.351 \mu \mathrm{m}$ through use off high quality optics and appropriate spatial filtering of the beams. A further study of the detailed focal plane irradiance and the effect of beam smoothing techniques is in progress.

The Beamlet prototype laser will be used to test long term integrated system performance over the next two years, using a configuration that is even closer to the actual NIF architecture. The preamplifier beam will be injected in the center of the transport spatial filter rather than the cavity spatial filter as in the present configuration. The frequency converter and final $0.351 \mu \mathrm{m}$ optics will be housed in a vacuum cell mounted onto Beamlet's final focus vacuum chamber. This configuration minimizes the total glass length exposed to the 0.351 $\mu \mathrm{m}$ laser beam, while the vacuum window of the system is exposed to the $1.05 \mu \mathrm{m}$ beam only. 


\section{ACKNOWLEDGMENTS}

We thank the Beamlet Operations and Engineering support teams for their efforts during the activation and experimental phase of the Beamlet laser facility. We greatly acknowledge the support by the Laser Modeling group and Filamentation Working group, and in particular the discussions with D.R. Speck, J.T. Hunt and J.A. Auerbach. E. Bliss, T. Salmon and M. Kartz lead the implementation and optimization of the deformable mirror wavefront control system.

This work was performed under the auspices of the U.S. Department of Energy by the Lawrence Livermore National Laboratory under contract number W7405-ENG-48.

\section{REFERENCES}

1. National Ignition Facility Conceptual Design Report, UCRL-PROP-1 17093 (May 1994) Available from the National Technical Information Service, Dept.of Commerce, 5285 Port Royal Rd., Springfield, VA 22161.

2. John Lindl, "Development of the indirect-drive approach to inertial confinement fusion and the target physics basis for ignition and gain," Phys. of Plasmas 2, 3933 (1995).

3. B. M. Van Wonterghem, J.R. Murray, J.H. Campbell, D.R. Speck, C.E. Barker, I.C. Smith, D.F. Browning and W.C. Behrendt, "System description and initial performance results for Beamlet", Lawrence Livermore National Laboratory report UCRL-LR-105821-93-1, ICF Quarterly Report 5-1, 1 (1993).

4. A. C. Erlandson, M. D. Rotter, K. S. Jancaitis, D. N. Frank, and R. W. McCracken, "Multisegment amplifiers for Beamlet and the National Ignition Facility", Proceedings of the first international conference on solid-state lasers for application to ICF, M. Andre and $\mathrm{H}$. Powell Eds, Proc. SPIE , 2633, 105 (1995).

5. M. A. Rhodes, B. Woods, J. J. DeYoreo, D. Roberts, and L. J. Atherton, "Performance of large-aperture optical switches for high-energy ICF lasers," Appl.Opt. 34, 5313 (1995)

6. J.T. Salmon, E.S. Bliss, J.L. Byrd, M. Feldman, M.A. Kartz, J.S. Toeppen, B. Van Wonterghem, and S.E. Winters, "An Adaptive Optics System for Solid-State Laser Systems used in Inertial Confinement Fusion", Proceedings of the first international conference on solid-state lasers for application to ICF, M. Andre and H. Powell Eds, Proc. SPIE, 2633, 105 (1995).

7. W. W. Simmons, J. T. Hunt, and W. E. Warren, "Light propagation through large laser systems," IEEE J. Quantum Electron. QE-17, 1727 (1981).

8. C. C. Widmayer J.M. Auerbach, R.B. Ehrlich, M.A. Hensian, J.T. Hunt e.a.,"Producing National Ignition Facility (NIF) - quality beams on the Nova and Beamlet lasers.", these proceedings.

9. J.T. Hunt, J. A. Glaze, W. W. Simmons, and P. Renard, "Suppression of self-focusing through low-pass spatial filtering and relay imaging, " Appl. Opt. 17, 2053 (1978).

10. P. Celliers, K. Estabrook, R. J. Wallace, J. E. Murray, L. B. Da Silva, B. J. MacGowan, B. M. Van Wonterghem, J. T. Hunt, K. Manes, "A novel spatial filter pinhole for high energy pulsed lasers", 24th European Conference on Laser Interaction with Matter, University of Madrid, Madrid, Spain, 3-7 June 1996.

11. R.S. Craxton, "Theory of high-efficiency third harmonic generation of high-power Nd-glass radiation," Opt. Commun. 34, 474 (1980)

12. C.E. Barker, B.M. Van Wonterghem, J.M. Auerbach, R.J. Foley, J.R. Murray, J.H. Campbell, J.A. Caird, D.R. Speck, and B. Woods, "Design and Performance of the Beamlet laser third harmonic frequency converter", Proceedings of the first international conference on solid-state lasers for application to ICF, M. Andre and H. Powell Eds, Proc. SPIE, 2633 398(1995).

13. C.E. Barker, R.A. Sacks, B.M. Van Wonterghem, J.A. Caird, J.R. Murray, J.H. Campbell, H.Kyle, R.B. Ehrlich and N.D. Nielsen, "Transverse stimulated Raman scattering in KDP", Proceedings of the first international conference on solid-state lasers for application to ICF, M. Andre and $\mathrm{H}$. Powell Eds, Proc. SPIE, 2633, 501 (1995).

14. S.N. Dixit, J.K. Lawson, K.R. Manes, H.T. Powell and K.A. Nugent, "Kinoform phase plates for focal plane irradiance profile control”, Opt. Lett, 19, 417 (1994).

15. P.J. Wegner, B.M. Van Wonterghem, S.N. Dixit, M.A. Henesian, C.E. Barker, C.E. Thompson, L.G. Seppala and J.A. Caird, "Characterization of third harmonic target plane irradiance on the National Ignition Facility Beamlet demonstration project.", these proceedings. 